\title{
Merleau-Ponty, Fenomenologia E Psicanálise
}

\author{
Claudinei Aparecido de Freitas da Silva ${ }^{I}$
}

\section{AYOUCH, Thamy. Maurice Merleau-Ponty ET LA PSYCHANALYSE: LA CONSONANCE IMPARFAITE. PARIS: Le Bord DE L'EAU, 2012, 201P.}

O livro Maurice Merleau-Ponty et la psychanalyse: la consonance imparfaite, pela Editora Le Bord de L'Eau constitui, seguramente, um marco na literatura filosófica francesa atual. Trata-se da obra de Thamy Ayouch, psicanalista, professor de psicopatologia clínica da Universidade de Lille 3 e pesquisador na Universidade Paris 7 - Denis Diderot. Como o título sugere, o trabalho explora um dos temas candentes ao longo de toda a reflexão do filósofo francês Maurice Merleau-Ponty (1908-1961), que parece ter concedido, cada vez mais, um certo lugar de honra da psicanálise naquilo que ela permite redimensionar questóes teóricas decisivas. Em tal contexto, que alcance maior o livro de Ayouch projeta, em meio à fortuna crítica literária em torno da obra fenomenológica de Merleau-Ponty?

Ao prefaciar o livro do psicanalista Angelo Hesnard, L' aeuvre de Freud et son importance pour le monde moderne, em 1960, pela Payot de Paris, MerleauPonty náo deixa de observar que "[...] é pelo que a fenomenologia subentende ou desvela em seu limite - por seu conteúdo latente ou inconsciente - que está em consonância com a psicanálise”. Essa observação explora, a bem da verdade, o estatuto de uma singular eufonia entre duas disciplinas habitualmente opostas em suas definições. Quer dizer, uma delas centra, com efeito, suas pesquisas sobre o fluxo da consciência, visando, a princípio, a descrever, de um modo mais rigoroso possível, o que aparece; a outra busca, sobre a camada do inconsciente, instituir um peso teórico às tendências supostas à base dos

\footnotetext{
${ }^{1}$ Professor dos Cursos de Graduação e de Pós-Graduação (Mestrado) em Filosofia da UNIOESTE Campus Toledo - com Pós-Doutorado pela Université Paris 1 - Panthéon-Sorbonne (2011/2012). E-mail: cafsilva@uol.com.br.
} 
fenômenos percebidos. Ora, prescrever qualquer analogia dessa ordem parece, à primeira vista, um tanto descabido, ainda mais se se levar a sério o argumento de Pontalis de que se está diante de um juízo que carece de maior comprovação junto à própria prática clínica. Tal é, segundo ele, o caso mais flagrante em que se situa a descrição fenomenológica de Merleau-Ponty. É afastando essa habitual crítica que Ayouch chama a atenção para o fato de que "MerleauPonty não estuda a psicanálise como doutrina à luz da filosofia [...]; ele se reserva ao direito de não se pronunciar sobre a prática analítica, inscrevendo seu discurso no campo teórico unicamente" (AYOUCH, 2012, p. 93). O que está em jogo, na proposição da "consonância", é a sondagem de uma racionalidade própria e, portanto, mais alargada que tornaria convergente, ambas as disciplinas. Para melhor compreender o alcance dessa tese aqui advogada pelo filósofo, será preciso, antes, situar qual "fenomenologia" é incorporada, por Merleau-Ponty, em suas relaçóes para com a psicanálise. Como já sublinhara Levinas, em seu instrutivo ensaio Reflexóes sobre a Técnica Fenomenológica, "[...] a fenomenologia é um método eminente, na medida em que se encontra essencialmente aberta”. Nessa direção, “[...] a obra de Husserl não parece haver atuado pelas suas consideraçóes metodológicas”, já que, na maioria das vezes, "[...] elas expressam muito mais posiçóes e respostas a problemas, que regras sobre a arte de tratá-las”. Se não há, conforme a apreciação levinasiana, uma direção unívoca na qual o movimento fenomenológico se orienta (sobretudo, em sua herança pós-husserliana), é porque se revive, agora, outro projeto tão complexo e de múltiplas facetas; programa esse, para parafrasear Ricœur, propositalmente "herético" em relação à sua fundação mais filialmente ortodoxa. É sob tal critério que a fenomenologia, em Merleau-Ponty, parece ganhar nova projeção, a ponto de se reformular radicalmente em meio a um movimento de franca abertura não só para com a psicanálise, mas para com outros setores do conhecimento. Nessa perspectiva, ela possui uma vocação transdisciplinar, de modo que Freud, ao lado de tantos outros, passaria a figurar como um de seus mais autênticos precursores quanto à compreensão última da natureza humana. Seria esse, então, um gênero de leitura completamente deslocado ou apressadamente ingênuo? É em meio a essa atmosfera de debate que o provocativo livro de Ayouch transporta o leitor e que, aqui, pretende-se, sumariamente, apreciar.

A princípio, é bem verdade que a premissa de uma fenomenologia do inconsciente não repercute qualquer consonância em meio à audiência das obras, não só de Husserl, mas igualmente de Heidegger ou até mesmo de Sartre. Tal abertura fenomenológica seria, de saída, facilmente refutada, pois 
muito se conhece a filiação terminológica da noção de inconsciente para com o vocabulário tradicional da metafísica, em sua herança mais espiritualmente cartesiana. Esse legado, aliás, o próprio Merleau-Ponty não deixará também de inventariar como um estigma ainda recalcitrante do idealismo clássico. Cumpre observar que a obra de Freud guarda, sobretudo, num primeiro momento, uma indisfarçável cumplicidade para com o naturalismo. Afinal, não se pode esquecer que o pai da psicanálise é um herdeiro direto do século XIX, momento esse em que se culmina um modelo explicativo predominantemente causalista, no que tange a certa cosmovisão de mundo e de homem.

Ora, para além desse legado consentido do freudismo, Merleau-Ponty quer mostrar o outro lado da moeda. Trata-se de abrir outra leitura inédita da psicanálise, naquilo que ela parece intuir de mais radicalmente fenomenológico. $\mathrm{Na}$ verdade, o que está em questão, nessa pauta, é uma releitura que vise a explorar não mais apenas um Freud naturalista, cartesiano de formação, mas um Freud devotado ou consagrado em conferir estatuto a uma dimensão do comportamento humano em sua mais plena fenomenalidade, até então não entrevista pela literatura médica de seu tempo. Todo ato humano tem um ou vários sentidos, postula ele. A sexualidade não é um ciclo autônomo: ela possui uma estrutura ontológica de primeira grandeza, e é esse domínio mais próprio que torna o projeto psicanalítico, uma "filosofia da carne", como iria caricaturar, anos mais tarde, Merleau-Ponty. Essa significação metafísica do corpo e da sexualidade não prescinde, portanto, de uma descrição tanto mais crítica quanto promotora no que concerne ao alcance conceitual do inconsciente. Se o termo parece impróprio, se essa fórmula signatária da teoria freudiana ainda se enuncia como um tanto restritiva, observa Merleau-Ponty, cumpre reconhecer, todavia, a que alcance ontofenomenológico ela visa ou, se quiser, qual é a sua maior intenção de princípio. Essa é uma crucial ordem de questão posta pelo livro de Ayouch: se, com efeito, a tentativa da fenomenologia consiste em ir do indeterminado à determinação ou, até mesmo, de instituir o sentido acerca do que aparentemente se revela inconsciente, como aplicar esta visada ao inconsciente psicanalítico sem, no entanto, reduzi-lo? O que significa, a rigor, um inconsciente paradoxalmente descrito, como propóe Merleau-Ponty, a partir da percepção?

O livro de Ayouch quer explorar, conforme seu subtítulo expressa, até onde essa suposta "consonância" entre a fenomenologia e a psicanálise, de fato, "perfeitamente" se legitima. É esse o pano de fundo da 2a Parte da obra, De la Psychanalyse à la Phénoménologie: Scansion du Contrepoint. No intuito 
de testar melhor essa hipótese interpretativa, o autor passa a examinar, dessa vez, a posição que assumirá o próprio movimento psicanalítico, trazendo, para a arena de combate, quatro grandes figuras de peso: Pontalis, Green, Lacan e Castoriadis. A eleição desses interlocutores não é casual, uma vez que, sob perspectivas diferentes, ora realçam a originalidade e o alcance do programa fenomenológico merleau-pontyano, ora sublinham o que este poderia manter ou guardar, como limite, do ponto de vista de uma confluência para com a psicanálise. Pontalis e Green observam, conjuntamente, que é a indistinção entre o inconsciente como ausência de tematização e o inconsciente propriamente psicanalítico que se torna um problema incontornável, pondo em xeque a tese da "consonância". Sob tal medida, se é bem-vinda a intuição merleau-pontyana de um "simbolismo originário do sonho" que se inscreve corporal ou carnalmente junto ao mundo, esse alcance, por outro lado, não se obtém, sem limites. O "olho clínico" de Pontalis foca um problema que parece irremediável: a tese da indivisão. Tudo se passa como se MerleauPonty confundisse "estrutura" e "significação". Pois bem, Ayouch chama a atenção para o quanto esse tipo de crítica não se aplica justo no caso de Merleau-Ponty, na medida em que "[...] uma filosofia do sentido não aceita o inconsciente senáo integrando-o a uma teoria do corpo sensível e da expressão" (AYOUCH, 2012, p. 133). Merleau-Ponty opera outra ideia de estrutura que difere, substancialmente, do estruturalismo, vindo a se aproximar, bem mais, da Gestalttheorie, resguardando-se, aqui, é claro, daquilo que esta ainda conservaria do realismo. O problema da indivisão, destaca Pontalis, é aquele a partir do qual Merleau-Ponty vê o inconsciente como o "outro lado" (Husserl) e não como a "outra cena” (Freud) de nossa existência. Esse "contrassenso", igualmente observado por Green, atesta uma dificuldade que, aliás, se prolongaria na obra tardia de Merleau-Ponty: a análise do corpo vidente-visível enquanto concepção tributária de uma filosofia da consciência, de maneira que o inconsciente não é somente o invisível, como também o que não participa daquele simbolismo primordial. $\mathrm{O}$ desejo não passa de uma interpretação; pior, ele é o fantasma mesmo de uma construção, o simbolismo secundário da linguagem. Dessa forma, enquanto, para Freud, o corpo permanece inteiramente libidinal, ele não é senão secundariamente libidinal, em Merleau-Ponty. Green, então, remata: a "ontologia da indivisão" de $O$ Visivel e o Invisivel não atende a uma camada mais elementar e, portanto, originária, ao abstrair os lugares dessa camada com o desejo. E a conclusão à qual chega Pontalis não poderia ser outra: não há experiência do sujeito do desejo, em Merleau-Ponty. Para fechar essa mútua leitura, a aporia calcada 
na ruptura entre consciente e inconsciente só pode situar o discurso merleaupontyano acerca da psicanálise como, flagrantemente, antifenomenológico.

Frente a tais objeçôes, Ayouch mobiliza um cuidado todo exegético em relação à tese merleau-pontyana da indivisão. É preciso reconhecer, à letra mesma do texto de Merleau-Ponty, que o invisível não se define como uma falta, mas como o inverso constitutivo do visível. Nessa redefinição, é o conceito kantiano de "grandeza negativa" que recebe uma audiência decisiva na obra do filósofo francês, no momento em que é articulada a sua concepção de inconsciente, para além de qualquer pressuposição simétrica. Ao mesmo tempo, a crítica quanto à omissão da especificidade do desejo se mostra uma exegese insustentável ante aquela referida obra. Assim é que, em seus cursos sobre a natureza (prolongando, em vários aspectos, o capítulo V, O Corpo como Ser Sexuado da Fenomenologia da Percepção), Merleau-Ponty póe em curso uma teoria do desejo. Como bem nota Ayouch, "[...] a sexualidade revela, aqui, uma corporeidade produtora de sentido" (p. 62). Num daqueles cursos, o fenomenólogo francês chegaria, inclusive, a problematizar o que seria o eu do desejo? Ora, esse eu só pode ser o corpo, isto é, o corpo em seu movimento mais ontologicamente radical deflagrado pela relação de princípio de nossa carnalidade com o mundo e com outrem. É aqui que o caráter indiviso do Ser como experiência "cria" e "tece", a todo tempo, aquela promiscuidade carnal. É nesse instante que a metáfora do quiasma entra em cena, figurando como a "verdade da harmonia preestabelecida" que torna reversível e não mais contraditório, o latente e o manifesto, a figura e o fundo de onde emerge. Sob esse ângulo, volta a observar Ayouch, a teoria merleau-pontyana do desejo parece central e decisiva: "Assim, em $O$ Visivel e o Invisivel, o desejo não é omitido, mas concebido ontologicamente: não se trata aqui de libido, de pulsão ou da perda do objeto primário, mas dessa abertura do corpo ao mundo [...]. O encontro com outrem me abre a um outro vidente que me une ao Ser e me torna visível a mim-mesmo; o desejo não se origina aqui de uma perda, mas de um encontro" (p. 149).

Não iremos pontuar, aqui, outras críticas disparadas de Green e de Pontalis comentadas por esse belíssimo ensaio de Ayouch. No restrito espaço do que aqui se resenha, cabe apenas situar essas já assinaladas por parecer estratégicas, na medida em que abrem ou estendem, mais proximamente, o canal de debate com Lacan e Castoriadis, ao advogarem a tese da "inconsonância". Lacan, nota Ayouch, acredita flagrar certo impasse do imaginário na fenomenologia de Merleau-Ponty. Esta se condenaria a 
ultrapassar o seu campo propriamente metodológico, tornando inacessível, a bem da verdade, uma experiência que lhe é estranha. Dessa feita, é a fundação merleau-pontyana do primado da percepção que torna inexequível ou mal sucedida a pretensa tentativa fenomenológica de atribuir estatuto ao inconsciente. É que, para Lacan, a percepção se torna, ela mesma, imaginária, de modo que é a partir da estrutura simbólica que o evento perceptivo deve, por fim, assentar-se. Qual o limite dessa leitura? Ayouch indica: essa crítica identifica o Imaginário em tudo onde não aparece, justo, o significante. Aí, a relação com outrem, por exemplo, se mostra impossível. Ou seja, Lacan torna essa relação como ilusória, condenando-a, junto com o corpo, a toda estrutura imaginária; relação, como se sabe, particularmente cara à fenomenologia.

Castoriadis, por sua vez, também pôe em questấo a teoria fenomenológica do inconsciente, na medida em que Merleau-Ponty não teria inteiramente se libertado do peso da herança clássica da ontologia. Expressão disso é o que ocorre, na emblemática passagem de $O$ Visivel e o Invisivel, em que a percepção é apresentada como sendo o "arquétipo do encontro originário"; encontro esse, "imitado e renovado no passado, pelo imaginário, pela ideia". Aos olhos de Castoriadis, haveria aqui o flagrante delito de uma equivalência entre a noção merleau-pontyana de percepção e a ordem da representação. Merleau-Ponty é então censurado por não proceder radicalmente à experiência filosófica do Ser, a partir do sonho. A esse modo, supõe o psicanalista, é o modelo do fantasmagórico que sustenta, a rigor, a realidade. É o domínio de uma imaginação radical, articulada à instituição social-histórica que constitui o primeiro plano do invisível, do inconsciente. Em tal escopo, a dificuldade dessa leitura é patente, como não deixa de argumentar Ayouch: MerleauPonty vê claramente "[...] uma homologia entre o Logos primeiro do perceber e o Logos segundo do pensar" (p. 180). O que carece ser reconhecido é que, para o fenomenólogo, o inconsciente não se descompromete com o simbólico, de maneira que a percepção revela o objeto "em carne e osso", diversamente de uma função representacional tomada em sentido estrito. $\mathrm{O}$ mundo percebido não rivaliza com o mundo histórico, já que a cisão entre natureza e cultura não passa de uma definição arbitrária, abstrata e, portanto, dogmática.

Em face desse balanço crítico da obra fenomenológica de MerleauPonty reapresentado, aqui, sumariamente por Ayouch, uma ordem de questáo parece inevitável: a partir de qual base exegética se entende ser insustentável a tese da consonância? A nosso ver, ela parece derivar de um incontornável vício de leitura que se tornou praticamente canônico, após os anos 1960, 
sobre o quadro mais geral da fenomenologia e, particularmente, da produção filosófica de Merleau-Ponty. Essa prática exegética consiste em ignorar, surpreendentemente, que cada um é cada um, ou seja, que Merleau-Ponty náo é Husserl, a ponto de se tornar um crítico visceral da própria fenomenologia, sem, no entanto, se desfiliar dela. O que tal exegese camufla é, pois, o avanço e o alcance programático da obra mesma de Merleau-Ponty, de modo que é mediante o "[...] desvio à fenomenologia husserliana" - acena Ayouch "[...] que pode surgir uma convergência entre fenomenologia e psicanálise" (p. 12). Assim, se for verdade, conforme se prefacia, na Fenomenologia da Percepção, que a fenomenologia é um estilo ou movimento antes mesmo de vir adquirir maior consciência filosófica; se for verdade, ainda, que ela não se resume, apenas, a uma "descrição de essências", mas recoloca "as essências na existência”, é sob este pano de fundo que a psicanálise pode, enfim, convergir, numa direção oposta não só a de Husserl, mas também à de Heidegger e a de Sartre. Será preciso, então, admitir que essa reorientação fenomenológica levada a cabo por Merleau-Ponty atesta o quanto ele é um autor atento da obra de Freud naquilo que esta, progressivamente, vai se revelando como projeto autocrítico. Como Ayouch observa, "Merleau-Ponty alarga a sua leitura de Freud" (p. 29), convidando a relê-lo como um clássico. O que Merleau-Ponty parece não perder de vista é o que Freud teria explorado de mais interessante, isto é, o de "[...] formular o tesouro de experiência que se oculta na comunicação psicanalítica”, a partir de um maior contato com as coisas, tornando-se, por conseguinte, "[...] soberano nessa escuta dos rumores de uma vida”. Ora, o que haveria de menos fenomenológico nisso? É nesse ponto, precisamente, que a psicanálise não constitui um domínio à parte, sem qualquer ressonância com os fenômenos. Na medida, portanto, em que amadurece, ela se exprime igualmente como uma "filosofia da carne", ou seja, promove aquela "reabilitação ontológica do sensível", instituindo outra ideia de homem e de verdade. Por isso, muito mais que um problema resoluto, a questão do inconsciente se apresenta como o índice dessa metamorfose, o enigma mesmo de uma ordem de experiência não mais locada no fundo da consciência, "atrás" de nós, mas, "lateralmente", em nosso campo perceptivo. Esse inconsciente será um "inconsciente carnal", a inscrição circundante de uma indivisão entre o interior e o exterior, o mundo e o corpo, eu e outrem. Ele é a prefiguração concreta de uma articulação de nosso campo; o "sentir mesmo" em sua primordialidade radical. Não é mais um objeto, mas aquilo que torna possível os objetos. Guardadas, portanto, as devidas distâncias, se a psicanálise nunca mais foi a mesma após Freud, a fenomenologia é outra, 
após Husserl. É sob esse horizonte aberto de leitura que se pode medir o real alcance da incursão fenomenológica de Merleau-Ponty no subsolo da práxis psicanalítica. É nesse entremeio que a inopinada "(im)perfeita consonância” se torna passível de ser discutida, como faz, exemplarmente, o livro de Ayouch. 